\title{
On the Ethics of Using Citation Indices in Evaluations
}

\author{
Raymond E. Spier
}

Received: 8 January 2009/ Accepted: 9 January 2009/Published online: 4 February 2009

(C) Springer Science+Business Media B.V. 2009

As dogma has it; the more a paper is cited the better it is. Is it? Papers in which there has been reason to question the experimental outcomes may be highly cited as interested parties seek to use such papers as examples of how not to behave. Two examples are the papers on cold fusion by M. Fleischmann and S. Pons in 1989 (391 citations) (Fleischmann et al. 1989) and on the memory of water by J. Benveniste in 1988 (225 citations) (Davenas et al. 1988) when a solution of an antibody is diluted to levels that probably do not contain any antibody molecules.

In the context of evaluating the worth of a particular paper it is well to note that there are many approaches that can be used. Does the paper report a discovery that leads to a valued product? Does the paper refute a hypothesis that is misleading? Does the paper provide understandings that unite a body of otherwise disparate knowledge? These questions are obvious. Conversely, we may have to consider the value of a paper that may be treated as insignificant at first sight but after a lengthy 'incubation' may stimulate researchers to achieve great and highly valued discoveries and products. The first papers in the areas of liquid crystals and lasers may be said to be of this nature.

In any analysis of citation data it is clear that in areas where there is great interest there are many research grants, journals, institutions and support and hence papers reporting on research in such areas are more liable to be highly cited. In areas where the topics are highly specialised there are correspondingly fewer citations-so to a first approximation citations do not evaluate the papers in an area but they are an index of the popularity of an area itself. Another reason for being cited more extensively is if the discovery reported fits into the developing jigsaw made up of bits of understanding leading to the appreciation of how a receptor works or how a cell walks. Again it is clear that if a researcher is working in the area of curing diseases (therapy) there are many more people working in this area than there are in

R. E. Spier $(\square)$

University of Surrey, Guildford, Surrey GU27XH, UK

e-mail: r.spier@surrey.ac.uk 
the area of preventing disease by, say, vaccination (prophylaxis) so the therapy papers are more highly cited than those dealing with prophylaxis. People researching the properties of food or pharmaceutical yeasts are usually most highly cited as their work speaks to people working in the areas of bread, cheese, milk, wine, antibiotics, infections and spoilage.

Looking at citations from the point of view of the citor, it can be said (normally through hear-say) that personal prejudices come into play. In the early days of Animal Cell Technology (before 1990), it used to be thought that Americans did not cite Europeans and vice versa. People who are well known in leading laboratories cite their own. The reputation of an author augers as much for the number of citations that person obtains as does the quality and value of the research. And, of course, the journal of publication is a primary determinant of the number of citations that accrue to a paper.

Papers that deal with new subject areas or in those areas that are a combination of well defined disciplines are generally not highly cited. A new area by definition lacks a well stocked constituency of researchers while the interdisciplinary areas are not only new but do not have the same kudos that intradisciplinary papers seem to possess. Also papers that deal with issues that are attractive to industry may lead to important advances in producing products but are not generally acknowledged as such by the commercial operator. Such papers are often recognised by the number of downloads from internet publications. This latter parameter is not used with the same frequency as the citation index yet in some circumstances it more accurately reflects the value of the paper to a research-active sector that is more secretive about its sources and ways of achieving success.

Notwithstanding the vagaries outlined above, the average number of citations per paper as a function of the particular journal is a decision-making parameter for individuals seeking homes for their publications. This composite index is surveyed with alacrity by publishers seeking to upgrade the quality of their stable of journals. Data are generated to determine which kinds of papers on what subjects attract the most citations and editors are informed of the resulting outcomes. So, standards are tightened and papers that are not likely to be cited become more difficult to publish. This, as suggested above, may or may not reflect how any one paper will influence the research that is to be conducted.

It is ironic that a paper that describes a method for the assay of proteins may be cited countless times, while another paper, mistaken in its conclusions, may evoke in others the desire to effect research that turns out to be of such value as to revolutionise either thought or practice in a particular area. We may come to conclude that although the number of citations of a given paper is a measurable parameter-that is all it is.

\section{References}

Davenas, E., Beauvais, F., Amara, J., Oberbaum, M., Robinzon, B., Miadonnai, A., et al. (1988). Human basophil degranulation triggered by very dilute antiserum against IgE. Nature, 333, 816-818. doi: $10.1038 / 333816 \mathrm{a} 0$.

Fleischmann, M., Pons, S., \& Hawkins, M. (1989). Electrochemically induced nuclear fusion of deuterium. Journal of Electroanalytical Chemistry, 261, 301; errata in Vol. 263. 